\title{
CONTRATOS DE CONDICIONES GENERALES: EL CONSUMIDOR Y CLÁUSULAS DE PERMANENCIA
}

\section{Eva del Pilar Plata Sarmiento}

Doctorado en Derecho (c.) Universidad Externado de Colombia (Colombia). Especialista en Derecho Administrativo, Universidad Santo Tomás Bucaramanga (Colombia). Abogada, Universidad Santo Tomás Bucaramanga (Colombia). Docente - Investigadora Facultad Derecho Universidad Santo Tomás Bucaramanga (Colombia). Correo electrónico: platasarmiento@gmail.com

\section{María Alejandra Castro Galán}

Especialización en Derecho Constitucional C., Universidad Santo Tomás Bucaramanga. Abogada Universidad Santo Tomás Bucaramanga. Joven Investigadora, Facultad de Derecho Universidad Santo Tomás Bucaramanga (Colombia). Correo electrónico: alejac_7@hotmail.com

\begin{abstract}
Resumen
Este escrito contiene el desarrollo de temáticas como los contratos de condiciones generales, en los cuales se incorpora la figura de la cláusula de permanencia mínima, se hace referencia en forma específica a los contratos de telefonía móvil en los cuales se estudia las situaciones constitutivas de cláusulas abusivas, para resaltar aquellos mecanismos de protección del consumidor frente a estas prácticas, como consecuencia en ocasiones de la misma naturaleza del contrato. Las cláusulas de permanencia presentes comúnmente en los contratos con condiciones generales, están delimitadas por un marco jurídico irradiado por principios constitucionales que desarrollan la temática contractual, a efectos de brindar garantías a las partes que deciden celebrar y dar curso a un contrato, es así que no solo se establece requisitos para su establecimiento, sino que también para efectos de poder establecer prórrogas automáticas frente a la prestación del servicio contratado. Asimismo frente al establecimiento de las cláusulas referidas se presenta una revisión del tema del consumidor a partir de una categoría en su denominación como "parte débil" en el contrato, haciendo mención al de adhesión, toda vez que se encuentra inmerso probablemente en situaciones de riesgo al momento de contratar; esto sucede debido a que la autonomía de la voluntad, se enfrenta con su única posibilidad de asumir la suscripción de un contrato con un clausulado preestablecido, donde sólo tiene la posibilidad de aceptar o rechazar el acuerdo elaborado por el predisponente.

Palabras clave: Cláusula de permanencia, Contrato de telefonía móvil, Contrato de Condiciones Generales, Cláusulas Abusivas, Consumidor.
\end{abstract}

\begin{abstract}
Within this research paper one shall find the development of subjects such as general conditions contracts, in which the figure of minimum duration provision is established, referring specifically to the mobile phone service provider contracts in which, moreover, abusive clause scenarios are studied in order to point out consumer protection mechanisms against such practices, as an occasional result of the nature of the contract itself. Minimum permanence provisions regularly present in the contracts containing general conditions are delimited by a legal framework instilled with constitutional principles that develop the contractual thematic, in order to offer guarantees to the parties executing and performing a contract. In such a way one does not only establish the requisites for its subscription, but for automatic extension purposes regarding the provision of the service as well. Therefore, vis-à-vis the inclusion of the referred clauses, a review on the consumer matter is presented taking as a starting point a label such as "the weak party" within the contract, in reference to standard form contracts, taking into account that the consumer might find itself involved in risky situations when subscribing the contract; the latter due to the fact that the freedom of will is forced to accept the execution of a contract with a default set of provisions, with the only possibilities to whether accept or decline the agreement format prescribed by the predisposing party.
\end{abstract}

Keywords: Clause of permanency, Contract of mobile telephony, Contract of General Conditions, Improper Clauses, Consumer.

\section{Résumé}

Cet écrit contient le développement de thématiques comme les contrats de conditions générales, dans lesquels s'incorpore la forme de la clause de permanence minimale, référence est faite dans une forme spécifique aux contrats de téléphonie mobile dans lesquels on étudie les situations constitutives de clauses abusives, pour ressortir ces mécanismes de protection du consommateur en face de ces pratiques, comme conséquence parfois de la même nature du contrat. Les clauses présentes de permanence communément dans les contrats avec des conditions générales, sont délimitées par un cadre juridique irradié par des principes constitutionnels qui développent la thématique contractuelle, aux effets d'offrir des garanties aux parties qu'ils décident de célébrer et de donner un cours à un contrat, il est donc non on établit seulement des conditions requises pour son établissement, mais aussi pour des effets de pouvoir établir des prorogations automatiques en face de la prestation du service commercé. De la même manière en face de l'établissement des clauses rapportées on présente une révision du sujet du consommateur à partir d'une catégorie dans sa dénomination comme «faible dépêche» dans le contrat, en faisant une mention à celui-là d'adhésion, étant donné qu'il trouve immergé probablement dans des situations de risque au moment de commercer; cela succède grâce à ce que l'autonomie de la volonté, il fait front à sa possibilité unique d'assumer la souscription d'un contrat avec un clauses préétabli, où seul il a la possibilité d'accepter ou de repousser l'accord élaboré par le prédisposent.

Mots-clés: Une clause de permanence, un Contrat de téléphonie mobile, un Contrat de Conditions Générales, une Clauses de Abusives, le Consommateur. 

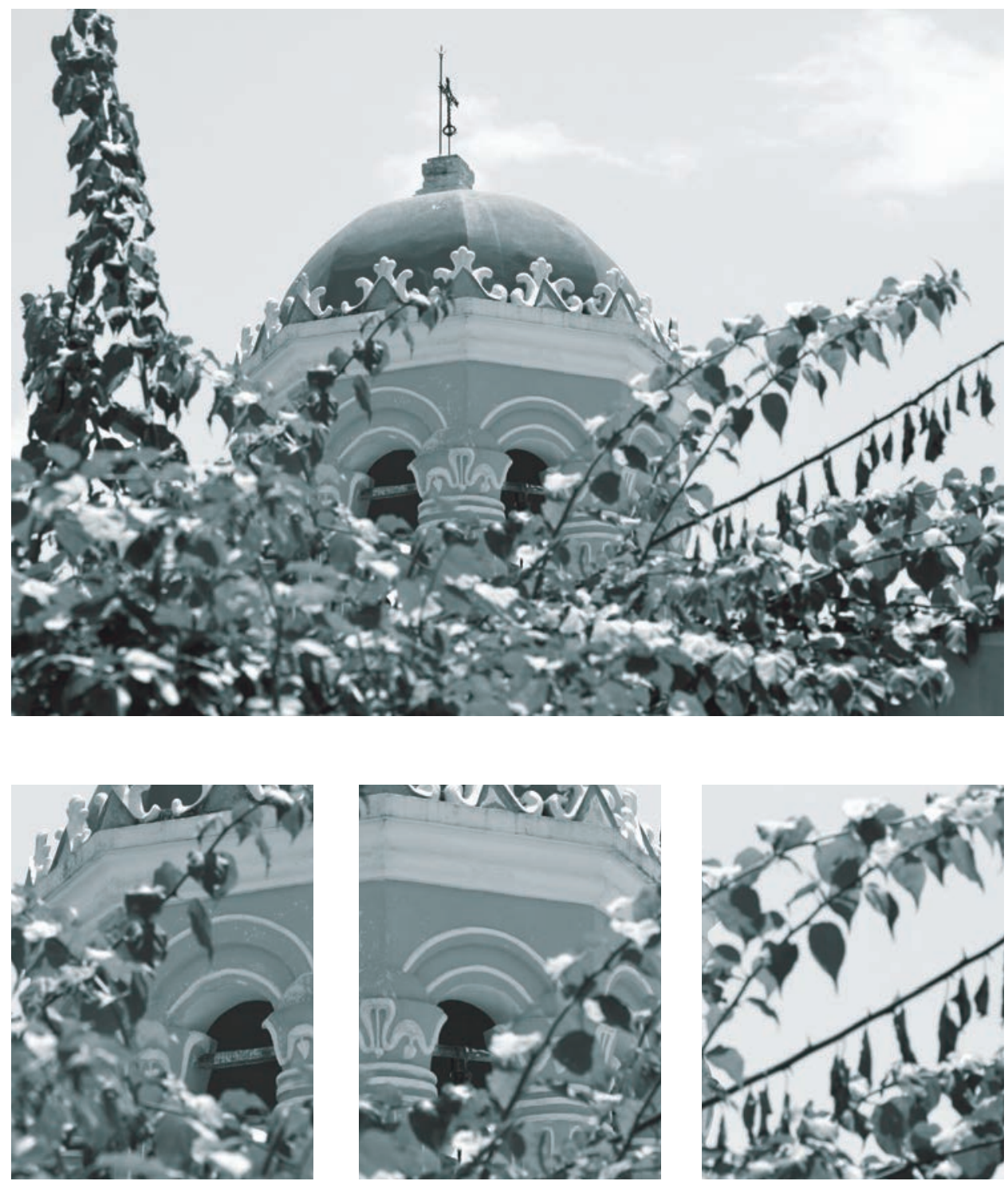

Iglesia de Santa Bárbara - Mompóx - Colombia

Martín Emilio Hernández Manrique 


\section{CONTRATOS DE CONDICIONES GENERALES: EL CONSUMIDOR Y CLÁUSULAS DE PERMANENCIA*}

Eva del Pilar Plata Sarmiento

María Alejandra Castro Galán

\section{Introducción}

En Colombia, constituye un tema de interés el estudio de las cláusulas abusivas en los contratos de condiciones generales, y de ahí, que se haga necesario el abordaje de temas como los contratos de adhesión, los contratos de telefonía móvil, las cláusulas de permanencia y el consumidor como sujeto pasivo que debe soportar la carga de estas cláusulas en la mayoría de las ocasiones.

El presente artículo está estructurado en tres capítulos, que responden al estudio del consumidor y la cláusula de permanencia dentro de los contratos de condiciones generales. Inicialmente se hace una aproximación a la cláusula de permanencia dentro de estos contratos, se establecen generalidades que identifican este tipo de contratación como escenario oportuno para que el predisponente incurra en actos nocivos para el consumidor, a partir del establecimiento de esta cláusula, en razón a ello, la imposición de la cláusula de permanencia dentro de estos contratos, debe estar delimitada por un marco jurídico que se desarrolla a partir de los principios constitucionales, mencionándose expresamente: el principio de buena fe, el equilibrio contractual, el abuso del derecho y la autonomía de la voluntad, no porque no existan otros que tengan incidencia en el tema, sino por ser estos quizás los más relevantes en razón de los temas medulares que se desarrollaron en la investigación soporte de este escrito.

* El presente artículo se presenta como resultado del proyecto de investigación: Cláusulas abusivas en los contratos de condiciones generales: una revisión a las formas adelantado por la autora, aprobado en Quinta Convocatoria Interna de Investigación Universidad Santo Tomás, BucaramangaColombia, en el marco del Grupo de Investigación Neoconstitucionalismo y Derecho de la Facultad de Derecho. Joven Investigadora: María Alejandra Castro Galán. 
Ahora bien, se enfoca este estudio, en el contrato de telefonía móvil, conceptualizado con las mismas características que el contrato de adhesión. A partir de este contrato se estudia la naturaleza del consumidor frente a la autonomía de la voluntad, al ser considerado como la "parte débil” ya que él, solo está en la facultad de aceptar o rechazar un clausulado ya establecido por la parte que tiene una posición de dominio, sin derecho a modificar aquellas cláusulas con las cuales quizás no se encuentra de acuerdo, lo cual no implica que por el hecho de la aceptación no se puedan hacer las revisiones necesarias al iter pactado, cuando de su contenido se advierta la existencia de abusos por parte del predisponente.

Como consecuencia de lo anterior, se desarrolla un tercer capítulo que da razón de aquellas cláusulas denominadas como abusivas, que aparecen con mayor frecuencia en los contratos con condiciones preestablecidas, tal y como es el caso del contrato de telefonía móvil. A su vez dentro de este tema se abordará el estudio de la presencia de estas cláusulas en los diferentes momentos del contrato esto es, en la celebración, ejecución o terminación del mismo, con miras a determinar las consecuencias de su inclusión frente al cumplimiento de las obligaciones pactadas.

\section{Aproximaciones a la cláusula de permanencia: contratos de condiciones generales}

Dentro de las posibles y variadas formas de contratar que hay en el tráfico comercial, se hace énfasis en los contratos de condiciones generales, siendo esta clase de contratación en masa, un escenario propicio para la estipulación de cláusulas de permanencia por parte del empresario, quien impone un clausulado, que decide aceptar o no el usuario del servicio, de acuerdo a las necesidades que busca satisfacer con la celebración del mismo.

En este sentido, se iniciará con algunas posiciones respecto a la conceptualización de los contratos de condiciones generales, con el fin de tomar como referencia un marco general de los mismos y terminar delimitando la cláusula de permanencia dada su injerencia en esta clase de contratación; respecto al tema, Laguado Giraldo establece:

Al hablar de esta clase de contratos es importante identificar los elementos esenciales de las condiciones generales: uniformidad, que hace referencia a su utilización en todos los contratos del mismo tipo; predisposición a su redacción previa; rigidez, en tanto a que el consumidor no las puede modificar ni evitar y, por último, el carácter empresarial del predisponente. (Laguado, 2003, p. 236).

Cabe señalar que cuando se hace referencia a los contratos de condiciones generales, se entiende como aquellos que contienen cláusulas predispuestas, redactadas por una sola de las partes con la finalidad de que estas sean incorporadas a varios contratos que se ofrecen a un número indeterminado de destinatarios.

Por ejemplo, para la contratación de servicios públicos domiciliarios y de aquellos servicios que se prestan en masa: seguros, telefonía móvil y televisión por 
cable, entre otros, es importante el establecimiento de condiciones generales las que “(...) son el resultado de la contratación masiva, de la necesidad de ahorrar costos y tiempo, del imperativo de dar igual tratamiento a todos los adherentes de esquemas negociales previamente determinados, de la necesidad económica y jurídica de aplicarlas uniformemente a una pluralidad de contratos y, en fin, de la urgencia de simplificar el iter formativo del contrato.” (Plata, 2010, p. 204).

Ahora bien, a partir de lo establecido en la teoría general del contrato, se tiene que estos contratos de condiciones generales hacen parte de los denominados contratos de adhesión, en razón de sus características referidas al establecimiento por una de las partes de las condiciones contractuales, para que la otra exprese su voluntad a través de la aceptación o no de la celebración del mismo, sólo para mencionar un aspecto incluyente en la definición.

La expresión contrato de adhesión ha sido atribuida al francés Saleilles, quien la acuñó a principios del siglo XX, definiéndolo así: "Los contratos de adhesión son aquellos en los que una de las partes contratantes, pone a la otra parte, en la alternativa de aceptar o rechazar la celebración de un contrato, quien debe aceptar íntegramente todas las condiciones fijadas". En nuestro criterio, el término contrato de adhesión transmite la idea de que dicho conjunto de normas tiene carácter convencional, es decir, deviene obligatorio en razón de la voluntad concordante de ambas partes. (Mendoza, 2007, p. 2).

En este mismo orden de ideas se extrae como una característica de los contratos de adhesión bajo condiciones generales la siguiente apreciación dada por Alonso Serrano Magistrado y Catedrático de Derecho Civil, en su ponencia interpretación de los contratos de adhesión expresa lo siguiente:

Una característica de los "contratos de adhesión bajo condiciones generales" es la de contemplar intereses generales o colectivos en los que es posible observar la confluencia de los intereses particulares de las partes del contrato, con intereses generales de la colectividad que explican la intervención estatal, no sólo en el control del contenido de dichos contratos, sino también estableciendo un sistema de autodefensa de la parte más débil del contrato que se engloba bajo la figura del "consumidor", mediante el cual se busca incrementar la protección del particular que se adhiere al contrato permitiendo que sus intereses sean asumidos por entes colegiados que agrupan a personas afectadas por idénticos intereses (...). Debe entenderse que la parte más débil del contrato es aquella que no ha tomado parte en la formulación y determinación de las diversas condiciones generales o particulares que integran el contrato, limitándose a dar su conformidad o aceptación a las que se le ofrecen o proponen, es decir, el adherente (Serrano (s.f.) ponencia).

El contrato de adhesión es "aquel en el cual el contenido contractual ha sido determinado con prelación por uno solo de los contratantes al que se deberá adherir el co-contratante que desea formalizar una obligación jurídica obligatoria" (Vallespinos, 1984, p. 238). 
Ballesteros Garrido (Las condiciones generales de los contratos y el principio de autonomía de la voluntad, 1999, p. 36) advierte que la forma de contratación por adhesión se usa no sólo para agilizar las operaciones, para lograr mayor eficiencia, para reducir costos, sino para asegurarse una posición de prevalencia en los acuerdos, beneficiando exclusivamente al predisponente a través de la imposición de prestaciones desequilibradas e injustas.

Es así, que dentro de las cláusulas predispuestas que se dan en estos contratos están las cláusulas de permanencia mínima, las cuales han sido definidas en el artículo 41 de la Ley 1480 de 2011, Estatuto del Consumidor. Tal denominación se entiende como un compromiso de estabilidad, donde se acuerda un período de tiempo en el que una parte (generalmente el usuario o consumidor) se obliga a mantener una relación contractual con la otra, a cambio del beneficio de conseguir una ventaja material imposible de adquirir libremente.

La cláusula de permanencia debe estar delimitada por un marco jurídico que se corresponda con los principios constitucionales; a partir de estos, se brindan herramientas al consumidor para que pueda hacer ejercicio de los derechos que goza frente al abuso en el establecimiento de dicha cláusula.

\section{Delimitación de la Cláusula de Permanencia: Principios Constitucionales}

Considerada la incidencia de un Estado Social y Democrático de Derecho en Colombia y consecuentemente la irradiación de principios constitucionales dentro del ordenamiento jurídico colombiano, a continuación se da desarrollo a algunos principios bajo los cuales se podría delimitar el concepto, finalidad y forma de incorporación de la cláusula de permanencia en el contrato.

Al respecto se trae a colación la siguiente cita expresada por el Doctor Alexey Julio Estrada en su ponencia titulada: la eficacia entre particulares de los derechos fundamentales. Una presentación del caso colombiano.

Los derechos fundamentales no cumplen su papel tradicional de derechos de defensa frente al Estado, sino como valores supremos dentro del ordenamiento jurídico, también fungen como mandatos de actuación y deberes de protección para los poderes públicos, al mismo tiempo que informan las relaciones recíprocas entre particulares y actúan como límites a la autonomía privada (...) en efecto la caracterización de la Constitución como "ley superior", con fuerza normativa propia, dentro de la cual los derechos fundamentales ocupan un lugar preponderante, sirvió de base para un inusitado desarrollo de la dogmática constitucional en los últimos tiempos y particularmente de la teoría de los derechos fundamentales, pues como afirma Pedro Vega, el derecho constitucional debe contemplarse hoy en día ante todo como un derecho de garantías (Estrada, (s.f.), p. 268).

En razón de lo anterior y partiendo de la incidencia que tiene el principio de la buena fe en todas las actuaciones de los ciudadanos, se iniciará su estudio a partir 
de la especificación de su desarrollo en las relaciones contractuales. Al respecto la Constitución Política de Colombia en su artículo 83 expresa lo siguiente: "Las actuaciones de los particulares y de las autoridades públicas deberán ceñirse a los postulados de la buena fe, la cual se presumirá en todas las gestiones que aquellos adelanten ante éstas".

Para contextualizar su desarrollo en el presente trabajo es oportuno traer a colación la definición que algunos doctrinantes del derecho le han dado a este:

El profesor Guillermo Ospina Fernández lo define así: los actos jurídicos deben ser cumplidos de buena fe, con entera lealtad, con intención recta y positiva, para que así pueda realizarse cabal y satisfactoriamente la finalidad social y privada a que obedece su celebración (...) tiene un alcance muy general en el derecho civil moderno, como quiera que es aplicable no-solo a los contratos, sino a todos los actos jurídicos y, lo que es más, a todas las obligaciones, cualesquiera que sean sus fuentes (...). (Ospina, 1998, p.331). Jaime Arrubla Paucar, expresa:

La buena fe es un concepto ético de antiquísima aparición, que ilustra instituciones filosóficas morales y jurídicas, y que se halla en permanente evolución. Es un concepto dinámico y no estático; aunque mantiene su idiosincrasia como base, ello no le impide actualizarse conforme a la evolución que experimentan los cambios políticos y sociales de los pueblos. (Arrubla, 1997, p. 97).

Jorge Suescún Melo expone que:

El principio de la buena fe obliga a los contratantes a actuar con lealtad y con la real intención de que, a través del cumplimiento de la prestación, se logren las finalidades económicas, jurídicas y sociales perseguidas con la celebración del acto. El señalado principio es en consecuencia una guía importante para la interpretación de los contratos a fin de determinar su espíritu y finalidad. Con el propósito de fijar el contenido del acto y de las obligaciones resultantes las partes y el juez deben, entonces, consultar la intención real, las normas propias de la naturaleza del acto y de sus obligaciones, las costumbres imperantes y los postulados de la equidad. (Suescún 1996, p. 18).

Valencia Zea, le da el siguiente significado:

cada cual debe celebrar sus negocios, cumplir sus obligaciones y, en general, ejercer sus derechos, mediante el empleo de una conducta de fidelidad, o sea, por medio de la lealtad y sinceridad que imperan en una comunidad de hombres dotados de criterio honesto y razonable. La buena fe se desdobla en dos aspectos: primeramente cada persona debe usar para con aquel con quien establece una relación jurídica, una conducta sincera, vale decir, ajustada a las exigencias del decoro social; en segundo término, cada persona tiene derecho a esperar de la otra esa misma lealtad o fidelidad. En el primer caso, se trata de una buena fe activa, y en el segundo, de una buena fe pasiva, confianza (Valencia 1981, p. 196). 
Lo anterior evidencia cómo cada autor presenta un significado propio de este principio, y que ellos no contienen todas las definiciones, no obstante no difieren de los elementos esenciales correspondientes al deber de actuar de tal manera que se desarrollen los comportamientos en forma seria, responsable, sin intención de infringir y dañar al otro, por ejemplo, dando la información veraz y suficiente respecto del negocio que se va a celebrar lo que de una u otra forma permite al consumidor tener mayor certeza y conocer las razones por las cuales debe tener la obligación de permanencia frente a la celebración de un contrato que contenga esta cláusula.

Es así que, la buena fe sirve como limitación al ejercicio de los derechos subjetivos al proscribir el abuso o la desviación en su ejercicio, e impulsa a las partes a ser coherentes en su comportamiento, pues evita contradecir sus propios actos, entre otras conductas. (Solarte, 2004, p. 289).

De acuerdo a lo anterior, se debe tener en cuenta que en el momento de suscribir un contrato que contenga la cláusula de permanencia mínima, es obligatorio el actuar de buena fe por parte del contratante, ya que es éste, quien tiene a su cargo la redacción del clausulado, no obstante ello, el contratista debe a su vez cumplir con los deberes de lealtad, probidad y responsabilidad frente a lo pactado, pues en ningún caso es válido frente a relaciones contractuales pasar por alto el cumplimiento de los deberes que el principio de buena fe irradia a quienes involucra el negocio celebrado.

Otro principio que se debe tener en cuenta con la suscripción de estas cláusulas de permanencia es el de la Autonomía, ya que a través de este, el derecho concede la facultad a los particulares de regular sus intereses; así es como, el individuo está guiado por sus propios intereses y sus necesidades, sin embargo, tal y como se establece el artículo 333 de la Constitución Política de Colombia "la actividad económica y la iniciativa privada son libres, dentro de los límites del bien común (...)."

Con el fin de revisar algunos aspectos generales de este principio, se traen a colación algunos autores que han conceptuado acerca del mismo.

Según Emilio Betti en su libro Teoría general del Negocio Jurídico expresa:

La autonomía privada es reconocida por el orden jurídico, en el campo del derecho privado, (...). Es decir como actividad y potestad creadora, modificadora o extintiva, de las relaciones jurídicas entre individuo e individuo; relaciones cuya vida y vicisitudes están ya disciplinadas por normas jurídicas existentes. La manifestación suprema de esta autonomía es el negocio jurídico (...) la autonomía privada configura también una autorregulación $\mathrm{y}$, específicamente, una regulación directa, individual, concreta, de determinados intereses propios, por obra de los mismos interesados. Entre el interés regulado y la libertad reguladora (este es el punto característico) existe aquí inmediata coincidencia, porque son, interés y voluntad, de las mismas personas. (Betti, 2008, pp. 52-53). 
Si bien es cierto el individuo debe hacer ejercicio de su voluntad libre de apremios para celebrar cualquier negocio jurídico, no se exime de tal exigencia la celebración de contratos de adhesión, en los que la autonomía de la voluntad encuentra su desarrollo a partir del momento en que la parte que se adhiere, acepta, las condiciones preestablecidas por el contratante.

Como complemento a la anterior afirmación se extrae la siguiente cita:

El contrato de adhesión desde su aparición generó debate en la doctrina acerca de su verdadera naturaleza jurídica, al respecto surgieron varias posiciones, la tesis contractualista que defendía la existencia de un acuerdo de voluntades en estos contratos, la tesis anti-contractualista, cuyo principal exponente fue Duguit, que negaba la existencia de un verdadero acuerdo de voluntades. Sin embargo, hoy en día a pesar que aúnexiste esta discusión no se le niega la categoría de verdadero contrato, al contrato de adhesión. (Villalba, 2009, p. 144).

Es así, que el principio de la autonomía de la voluntad, al igual que en un contrato desde la concepción tradicional se ve reflejado en un contrato de adhesión, ya que aunque esta se manifieste con solo una aceptación o un rechazo, se considera como una válida expresión de voluntad en la legislación colombiana.

Ahora bien, asumida la presencia de la buena fe, la autonomía de la voluntad en las relaciones contractuales y específicamente en los contratos de condiciones generales, el siguiente principio que se debe abordar es el del equilibrio contractual: Como bien anota FINLANGER: el principio del equilibrio contractual aparece hoy como un instrumento de conocimiento y comprensión de la teoría del contrato que posibilita establecer su alcance. A través de él se proyecta una visión más justa y solidaria del contrato, respalda su presencia al estar fundada en la buena fe contractual.

GUAL ACOSTA destaca que el principio del equilibrio contractual se deduce de la vigencia de los valores tales como la justicia que vela por el equilibrio de las prestaciones y la buena fe como conducta debida. El código civil colombiano está estructurado sobre la idea de que la libertad contractual permita el control y el equilibrio contractual. Las reglas sobre la regulación de los vicios de la voluntad, en definitiva como advierte FINLANGER, son una forma indirecta de tutelar el equilibrio contractual. (Ordoqui, 2010, p.179).

Habida cuenta que a través del principio del equilibrio negocial se estatuye una nivelación en las cargas que se derivan del iter contractual, es posible entrar a analizar en el caso del establecimiento de la cláusula de permanencia, sí este principio continúa vigente; al respecto la parte contratante para equilibrar las cargas, al hacer esta inclusión en el contrato, está en el deber de ofrecer algunas garantías al usuario, las que se describen en el artículo 41 de la ley 1480 de 2011- Estatuto del Consumidor, sin que estas sean las únicas, pues en materia de comunicaciones se deben traer a colación también las correspondientes Resoluciones emanadas de la Comisión de Regulación de Comunicaciones. 
Ahora bien, los principios que sirven como base a la delimitación de los alcances de la cláusula de permanencia y realizada una conexión entre el principio de la buena fe y el del equilibrio contractual, es pertinente entrar a exponer el principio del abuso del derecho.

Según este principio, los derechos de los individuos no son absolutos sino relativos, y no pueden hacerse uso de ellos sino con motivo legítimo y noble y sin apartarse del espíritu que los inspira. Por lo tanto, la persona que en el ejercicio abusivo de sus derechos ocasione perjuicio a otra debe indemnizar (...). Como ejemplos de este principio se puede señalar los siguientes: embargo en exceso de bienes del deudor, el abuso del derecho a litigar, la formulación temeraria de denuncia criminal, cuando se insiste en el secuestro de bienes que no pertenecen al ejecutado. (González, 1988, p. 169).

El abuso de derecho, en tanto principio general, es un instrumento del cual se vale el operador jurídico para lograr una correcta y justa administración de justicia. Es aquí donde juega un rol decisivo la labor creativa y prudente del juez que debe estar atento a reconocer nuevos intereses existenciales y patrimoniales, enfrentando audazmente modelos legislativos que los pretenden inmovilizar. (Espinoza, 2005, p. 131).

Además de las anteriores definiciones, aparece otra que además le cataloga como un principio general del Derecho al señalar: "El abuso del derecho es un principio general (...) según el cual nadie puede ejercer sus derechos con desmedro, de la función social que le es inherente" (Chapman, 2004).

A partir de este principio, se presentará la conexión con las cláusulas abusivas, ya que cuando se está en presencia del abuso del derecho en un contrato de adhesión por la imposición de la cláusula de permanencia que no responde a su naturaleza, se da un aprovechamiento por el predisponente del servicio, que debe ser objeto de sanción.

Teniendo en cuenta el desarrollo anterior se presenta únicamente estos principios toda vez que en nuestro estudio son los que direccionan la investigación propuesta, sin embargo, no queremos pasar por alto la incidencia de otros que si bien expresamente no se mencionan necesariamente deben avocarse precisamente por la connotación que tiene el estudio del derecho a partir de teorías como el Neoconstitucionalismo, a través de la cual no es posible entender el ordenamiento jurídico colombiano por fuera de un sistema en el que se dinamizan las normas, reglas y principios.

En este orden de ideas, es oportuno entrar a mencionar otro aspecto, generado a partir de la cláusula de permanencia, y es el que hace referencia a las prórrogas automáticas. 


\section{Cláusula de permanencia frente a las prórrogas automáticas}

Respecto a la cláusula de permanencia y las prórrogas automáticas, se da inicio con el siguiente postulado dado por la Comisión de Regulación de Comunicaciones, donde se establece el Régimen Integral de Protección de los Derechos de los Usuarios de los Servicios de Comunicaciones que mediante Resolución 3066 de 2011 y más específicamente en sus artículos 17 y 18 estipula:

las cláusulas de permanencia mínima y prórrogas automáticas, sólo podrán ser aplicables cuando medie aceptación escrita del usuario que celebró el contrato, a su vez solo podrán ser pactadas únicamente cuando se ofrezcan planes que financien o subsidien el cargo por conexión, equipos terminales $\mathrm{u}$ otros equipos de usuario requeridos para el uso del servicio contratado, o cuando se incluyan tarifas especiales que impliquen un descuento sustancial, y se pactarán por una sola vez, al inicio del contrato. El período de permanencia mínima nunca podrá ser superior a un año, salvo que el proveedor que financie o subsidie equipos terminales requeridos para la contratación del servicio de acceso a Internet, acuerde con el usuario la inclusión de una cláusula de permanencia mínima que en ningún caso podrá ser superior a treinta y seis (36) meses.

El monto de los valores a pagar por terminación anticipada no podrá ser mayor al saldo de la financiación o subsidio del cargo por conexión o equipos terminales u otros equipos requeridos para el uso del servicio contratado, o al descuento sustancial por tarifas especiales, que generó la cláusula de permanencia mínima.

En los contratos con cláusulas de permanencia mínima, en los cuales se pacte la prórroga automática, debe informarse desde el momento de la oferta que, una vez cumplido el término de la permanencia mínima, se entenderán prorrogadas las condiciones y términos originalmente pactados, salvo aquéllas condiciones asociadas al valor del subsidio y/o financiamiento del equipo terminal u otros equipos requeridos para el uso del servicio contratado o del cargo por conexión.

Adicionalmente, al prorrogarse automáticamente el contrato, el usuario que lo celebró no estará sujeto a la permanencia mínima inicialmente convenida, por lo que tendrá derecho a terminar el contrato en cualquier momento durante la vigencia de la prórroga sin que haya lugar al pago de sumas relacionadas con la terminación anticipada del contrato, salvo que durante dicho período se haya pactado una nueva cláusula de permanencia mínima, para el caso en que el proveedor financie o subsidie un nuevo equipo terminal $u$ otros equipos requeridos para el uso del servicio contratado. A su vez esta cláusula debe redactarse de manera clara y expresa, de tal manera que resulte comprensible para el usuario.

Cuando el proveedor ofrezca contratos con cláusula de permanencia mínima, ésta debe ir en anexo separado del contrato, se deberá incorporar en su inicio, en letra de tamaño no inferior a cinco (5) milímetros y en un color diferente al del contrato, según lo establecido en el artículo 18 de la resolución mencionada. 
Es importante señalar la conexión que existe entre la anterior Resolución y el actual Estatuto del consumidor, en cuanto a la incorporación de la cláusula de permanencia en el contrato; el Estatuto del consumidor hace mención de la incorporación de estas cláusulas en los contratos de tracto sucesivo, es decir, en aquellos contratos en que se da un pago periódico por el servicio prestado. En ambas normativas expresamente se establecen condiciones de equilibrio para poder pactar dichas cláusulas, además del tiempo que hace referencia a (1 año) con excepción de dos casos: que explícitamente se señalan en el Estatuto del consumidor: acordar nuevas condiciones que impliquen una ventaja sustancial frente a las condiciones ordinarias del contrato, dada por el proveedor del servicio y otra, hace referencia a una autorización por parte de la Superintendencia de Industria y Comercio; por otro lado, en la mencionada Resolución se plasma que es viable pactar que el tiempo de la permanencia sea superior solo porque medie un acuerdo entre las partes y agrega además, que otra situación es la financiación o el subsidio de equipos terminales específicamente de servicios de Internet, pero que no puede pasar de (36 meses), siendo normativas complementarias frente al tema referido.

Es así que se debe ser claro con el usuario al momento de establecer una cláusula de permanencia, todas las obligaciones pactadas al inicio en el acuerdo contractual deben ser establecidas de manera precisa, por ello se exige la visibilidad en el establecimiento de esta cláusula con el fin de evitar que se dé lugar a engaño o falta de información completa y veraz para el consumidor o usuario.

El proveedor del servicio, al ser considerado como la parte dominante en el contrato, tiene el deber de lealtad para actuar en las relaciones contractuales. Situación que se espera sea realizada y acatada, ya que cada día surge un sinnúmero de contratos que dan paso al incumplimiento de algunos aspectos que son esenciales en cuanto a la garantía de los derechos de los usuarios quienes no recurren a atacar el contrato en ocasiones por las dificultades de tiempo y la poca accesibilidad a una escucha adecuada por parte de los prestadores de los servicios, quienes se atienen al tenor literal del contrato y olvidan las circunstancias de tiempo, modo y lugar que de manera específica pueden afectar la prestación contratada.

Ahora bien, luego de haber expuesto algunos compromisos con los que el proveedor debe llevar a cabo legalmente su procedimiento, tanto en la oferta como en la ejecución del contrato, se entra a estudiar un caso específico a través del siguiente concepto de la Comisión Nacional de Televisión que señala uno de los aspectos que va en detrimento económico del consumidor y que ha hecho camino en diferentes servicios públicos, este es, el del aumento de la tarifa inicial respaldada en la cláusula de permanencia, sin embargo esta situación según la Comisión no se puede generar ya que:

Cuando en un contrato de televisión por suscripción, la cláusula de permanencia mínima se encuentra vigente, el operador no puede incrementar la tarifa inicial de acuerdo con el esquema de incrementos pactados en el contrato, toda vez que en este caso la vigencia del plan tarifario es la misma de la cláusula de permanencia, 
e incluye los incrementos previstos en el contrato. Si el operador modifica la tarifa cuando la cláusula de permanencia mínima se encuentra vigente, el suscriptor podrá terminar el contrato de forma unilateral, dentro del mes siguiente al momento de conocer la modificación, sin que haya lugar a multa o sanción, incluso durante la vigencia de la cláusula de permanencia mínima”. (Comisión Nacional de Televisión, Concepto 88453 de 2009).

El empresario está en todo su derecho de pactar la cláusula de permanencia mínima, siempre y cuando no sobrepase los postulados legales que deben ser acogidos, y que como ejemplo fueron sustentados anteriormente, sin que estos sean los únicos casos que se puedan plantear. Los mínimos que deben ser respetados al incluir la cláusula de permanencia en un contrato son: dar información veraz y suficiente acerca de la imposición de estas cláusulas, como por ejemplo: duración exacta del contrato, posibilidad de generarse las prórrogas, informar si en la ejecución se presentan cambios en el acuerdo, en todo caso evidenciar un proceder de acuerdo a la buena fe, que debe preceder todas las negociaciones que se asuman, conforme lo dispone el artículo 83 de la Constitución Política de Colombia, cuando establece: "las actuaciones de los particulares y de las autoridades públicas deberán ceñirse a los postulados de la buena fe, la cual se presumirá en todas las gestiones que aquéllos adelanten ante éstas". Otro postulado que debe ser tenido en cuenta para justificar la inclusión y exigencia de la cláusula de permanencia corresponde a la calidad en la prestación del servicio, y que tiene relación con el respeto de la premisa pacta sunt servanda, esto es, que se preste acorde a lo convenido entre las dos partes, que no se aumente la tarifa inicialmente pactada por el término de permanencia y que se ha querido evidenciar a través de la siguiente premisa:

\begin{abstract}
Los usuarios y los proveedores de servicios de comunicaciones deben respetar los derechos y obligaciones que se derivan para cada una de las partes como consecuencia del contrato de prestación de servicios de comunicaciones, de acuerdo con lo establecido en la ley y la regulación vigente. En igual sentido, en todo momento, debe existir reciprocidad en el trato respetuoso que se deben mutuamente el proveedor de servicios de comunicaciones y los usuarios, tanto en la oferta, como en la celebración del contrato y durante su ejecución. (Artículo 5 Resolución 3066 De 2011de la Comisión de Regulación de Comunicaciones).
\end{abstract}

Con todo lo anterior, quedan plasmadas en forma general algunas normativas que posibilitan las prórrogas automáticas de la cláusula de permanencia, lo cual no puede ser estudiado en forma aislada, sino tenido en cuenta los casos específicos y las reglamentaciones establecidas para ello, y en todo caso contar con el respaldo de los principios constitucionales que dentro del Estado Social y Democrático de Derecho, irradian el ordenamiento colombiano, y en el caso objeto de estudio delimitan la cláusula de permanencia presente en las relaciones contractuales tal y como se expuso al inicio de este título. 
El consumidor la parte a quien corresponde asumir las disposiciones previamente aceptadas mediante la celebración del contrato de condiciones generales, se hace necesario un análisis de su quehacer, participación activa y pasiva al interior de contrato de telefonía móvil.

\section{El consumidor: sujeto, en el contrato de telefonía móvil}

\section{De la naturaleza del consumidor}

En el mundo existen, diferentes relaciones contractuales, que se direccionan en su mayoría hacia fines económicos, es allí, a través de la oferta de bienes y servicios por parte del empresario o productor, que se encuentra el destinatario (usuario o consumidor), como principal accionante del negocio, hacia quien se focaliza la satisfacción de necesidades, de acuerdo al objeto empresarial trazado.

Considerada la relación anteriormente enunciada, surgen dos figuras en dicho trato:

El productor o distribuidor de bienes y el sujeto que tiene la necesidad de aprovechar tal bien, creándose de esta manera la figura del consumidor, destinatario de toda relación comercial - jurídica, y es el último en la escala jerárquica del objeto industrial y comercial. Para aclarar el concepto, Berkemeyer Hugo (Protección jurídica del consumidor y usuario. Asunción: Intercontinental Studio, 1991, p. 20.) plantea acerca de la noción de consumidor que en la antigüedad, se consideraba así a quien adquiría cualquier clase de producto, posteriormente, se amplió ese concepto con la incorporación del término usuario al sistema de protección, que originariamente se refería sólo al consumidor.

Lazzarini, de Oliveira Ríos y Serrano Nunes Jr(Código de defesa do consumidor anotado e ejemplificado pelo IDEC. Citado por Ibíd., p. 21.) señalaron que la noción del consumidor como destinatario final, adoptada también por el artículo 2o. del código brasilero, se identifica con aquel que adquiere bienes o servicios para su uso o consumo personal o el de su familia. El parágrafo único del artículo 2 amplía la noción del consumidor al incorporar a las colectividades de personas que, aunque indeterminadas, hayan intervenido en la relación de consumo; un ejemplo lo constituiría una población que sufriera el efecto de la mala calidad del agua potable, aun cuando fuese indeterminado el número y la identidad de personas dañadas. (Ortiz \& Quintero 2008, p. 8).

Además de los anteriores señalamientos acerca del concepto de consumidor, se enuncian a continuación otras definiciones importantes al respecto, con las que se pretende mostrar un panorama amplio acerca de la figura y su incidencia frente al tema que en el presente se desarrolla:

Se puede considerar que el consumidor es el núcleo del sistema económico, pues la producción va a estar en función de la capacidad de adquisición de productos por 
parte de los consumidores. Dada esta importancia, el consumidor siente la necesidad de reclamar una cierta protección frente al resto de intervinientes en el mercado. Ya en el Siglo XVIII, Adam Smith veía en el consumo el único fin y objetivo de la producción y se lamentaba de la ya patente protección que en el orden económico se reserva a los productores en menoscabo de los intereses de los consumidores. (González, 2005. Pág. 37).

Es así que el consumidor se puede entender como toda persona natural, considerada motor de la economía, a quien se dirige constantemente ofertas de bienes y servicios, de ahí que sea necesario brindar protección total a sus frecuentes acciones contractuales, con el fin de generar proporcionalidad en sus relaciones jurídicas y estabilidad en la economía del país.

En Colombia, los derechos del consumidor son de carácter colectivo y tienen desarrollo en el Art. 78 de la Constitución Política, en la que se señalan las directrices necesarias no sólo para su protección, sino además los mecanismos de participación, dada la importancia que representa el consumidor en la toma de decisiones comerciales que les involucran frente a la puesta en escena de sus deberes y derechos. La Corte Constitucional en sentencia C-1141 de 2000 dispuso que:

Los derechos del consumidor, no se agotan en la legítima pretensión a obtener en el mercado, de los productores y distribuidores, bienes y servicios que reúnan unos requisitos mínimos de calidad y de aptitud para satisfacer sus necesidades, la cual hace parte del contenido esencial del derecho del consumidor. El derecho del consumidor, cabe advertir, tiene carácter poliédrico. Su objeto, en efecto, incorpora pretensiones, intereses y situaciones de orden sustancial (calidad de bienes y servicios; información); de orden procesal (exigibilidad judicial de garantías; indemnización de perjuicios por productos defectuosos; acciones de clase etc.); de orden participativo (frente a la administración pública y a los órganos reguladores)

La configuración sustancial y procesal de este aspecto - calidad de los bienes y servicios, del derecho del consumidor, según la Constitución Política, es del resorte del legislador. De una parte, el artículo 78 de la C.P., atribuye a la ley la función de regular el control de calidad de bienes y servicios ofrecidos y prestados a la comunidad; de otra parte, la misma norma constitucional hace responsables a los productores - además de los distribuidores - por "el adecuado aprovisionamiento a consumidores y usuarios", pero esta responsabilidad se establece "de acuerdo con la ley". (Corte Constitucional, Sala Plena, SentenciaC-1141, M.P Eduardo Cifuentes Muñoz De 2000).

Al llegar a este punto, es pertinente mencionar actualmente qué se ha regulado en Colombia respecto del consumidor, es así como se trae a colación el estatuto del consumidor promulgado a través de la ley 1480 de 2011.

En cuanto a la definición de consumidor o usuario, se tiene la contenida en el artículo 5 de la norma referida: 
Toda persona natural o jurídica que, como destinatario final, adquiera, disfrute o utilice un determinado producto, cualquiera que sea su naturaleza para la satisfacción de una necesidad propia, privada, familiar o doméstica y empresarial cuando no esté ligada intrínsecamente a su actividad económica. Se entenderá incluido en el concepto de consumidor el de usuario.

En la anterior definición, se denota que la ley ha preferido concebir al consumidor y usuario en el mismo sentido, debido a la confusión que se presentaba por su misma identificación, no obstante esta diferencia entre los dos conceptos se mantiene en normatividades especiales, tal es el caso de los servicios públicos domiciliarios, solo para citar un caso a manera de ejemplo (ley 142 de 1994). En el Decreto 3466 de 1982, se hacía referencia simplemente al término consumidor -Artículo 1, literal c Luego en la ley 1328 de 2009, se decidió separar estos en dos conceptos, definiendo a usuario como: "la persona natural o jurídica quien, sin ser cliente, utiliza los servicios de una entidad vigilada" (Artículo 2 literal b) y al consumidor financiero como: "todo cliente, usuario o cliente potencial de las entidades vigiladas." (Artículo 2 literal d)

Cabe precisar además de los señalamientos anteriores en relación con el tratamiento del consumidor o usuario, que a través de este nuevo estatuto, se le ha tomado como aquel destinatario final, que adquiera el servicio y es en relación con este aspecto, que se revisará la connotación de "parte débil" en la celebración de contratos de adhesión, frente al establecimiento de las cláusulas de permanencia.

Es así, que el consumidor designado como "parte débil" en el contrato, hace referencia a una de las partes que participa de los contratos de adhesión, al respecto Alonso Serrano, Magistrado y Catedrático de Derecho Civil, en su ponencia interpretación de los contratos de adhesión expresa lo siguiente:

Una característica de los "contratos de adhesión bajo condiciones generales" es la de contemplar intereses generales o colectivos en los que es posible observar la confluencia de los intereses particulares de las partes del contrato, con intereses generales de la colectividad que explican la intervención estatal, no sólo en el control del contenido de dichos contratos, sino también estableciendo sistema de autodefensa de la parte más débil del contrato que se engloba bajo la figura del "consumidor", mediante el cual se busca incrementar la protección del particular que se adhiere al contrato permitiendo que sus intereses sean asumidos por entes colegiados que agrupan a personas afectadas por idénticos intereses (...). Debe entenderse que la parte más débil del contrato es aquella que no ha tomado parte en la formulación y determinación de las diversas condiciones generales o particulares que integran el contrato, limitándose a dar su conformidad o aceptación a las que se le ofrecen o proponen, es decir, el adherente (Serrano s.f. Ponencia).

Como complemento a la anterior cita se trae a colación un aparte de un artículo de Estigarribia Bieber, María Laura, titulado Las Cláusulas Abusivas en la Contratación con Consumidores en la Legislación Argentina en el cual opina que: 
Nos encontramos con una parte fuerte, constituida por el experto - proveedor - predisponente, y una parte débil, encarnada por el profano - consumidor adherente. Esta disparidad de fuerza es la que pone de manifiesto la necesidad de la función tuitiva del Estado, a efectos de restituir, de algún modo, el equilibrio del sinalagma contractual. En reconocimiento de la vulnerabilidad del consumidor (Estigarribia, s.f.).

Respecto a la debilidad del consumidor debemos afirmar que ésta no tiene carácter contingente, sino estructural. El consumidor es la parte débil, por definición, en las relaciones de consumo. Como expresa Eric:

Si bien en un modelo de competencia perfecta ninguno de los agentes posee el poder suficiente para influir, con su comportamiento en los resultados del mercado, especialmente en la formación de los precios, decidiendo en última instancia el consumidor sobre cada uno de aquellos resultados, no puede decirse lo mismo cuando en el mercado existe una situación de poder, lo cual conduce a resultados diametralmente opuestos. Así pues, la posición de ventaja en el mercado, en la cual uno de los sujetos que participan en el proceso de intercambio dispone de un margen de actuación más amplio que los demás, determina un falseamiento de la inicial función desapoderadora de la competencia, puesto que, para dicho operador, los resultados del mercado (precios y demás) no constituyen fenómeno externo alguno, sino parte integrante de su estrategia empresarial (Reich, 1985, p. 159-160).

De lo presentado se fundamenta la definición de consumidor como "parte débil" del contrato, en todas aquellas relaciones de consumo, en la cuales este es categorizado como adherente. Esto, en razón a que el consumidor en estos casos no se encuentra en la facultad de redactar el clausulado del contrato al cual se va a suscribir, sino que se tiene que adherir a esas condiciones generales ya preestablecidas por la otra parte que se designa como en la anterior cita de Estigarribia la "parte fuerte". Por lo tanto, con este análisis lo que se quiere dar a entender, es que frente a una desventaja que se le presenta al consumidor en la suscripción de estos contratos, tiene que haber una ventaja que equipare y equilibre sus derechos con respecto a los de el predisponente o el empresario.

Respecto a la anterior apreciación, es pertinente mencionar la siguiente cita que Rinessi expone en su artículo Relación del Consumo y Derechos del Consumidor:

Hay asimetría en toda relación en la que exista una parte con un poder contractual predominante sobre la otra, sea por su nivel de conocimiento, sea por su poder de negociación, o sea por las características de los productos que produce o comercializa. Tales circunstancias propician situaciones que afectan la libertad contractual, comportan abuso de derecho, generan desequilibrios, establecen condiciones generales sorpresivas o disimuladas, en suma, situaciones que vulneran los postulados de la buena fe objetiva. (Rinessi, 2006, p.27)

Como consecuencia de esta explicación dada por Rinessi, es que se puede decir que: "nuestro ordenamiento jurídico ha estructurado el tratamiento del contrato con 
el consumidor bajo el paradigma de la asimetría contractual entre empresarios y consumidores". (Granados, 2012, p. 28).

Sentada como precedente la situación del consumidor, quien en la suscripción de un contrato con condiciones predispuestas, en el cual ya se ha incorporado la cláusula de permanencia como sucede en el caso del contrato de telefonía móvil, la única opción que le queda es aceptar o rechazar la suscripción de este contrato, se le brinda protección, con el fin de equilibrar aquellas asimetrías que se presentan, y más cuando de la cláusula de permanencia se trata. Sin embargo, pese a que estas cláusulas tienen respaldo legal, en muchas ocasiones pueden llegar a constituirse en cláusulas abusivas, no por el hecho de establecerse en un contrato, sino por sobrepasar los límites que la misma normatividad le ha impuesto, este es un ejemplo de mecanismo de defensa de los derechos del consumidor, al poder elevar las reclamaciones respecto al aparecimiento de estas cláusulas en el contrato.

Si bien es cierto el status de consumidor se adquiere dados los presupuestos señalados en forma precedente, es importante anotar que tal calidad tiene relación directa con el contrato que se celebra, de ahí que a continuación se presente cómo se perfecciona la autonomía de la voluntad en el contrato de adhesión.

\section{El contrato de adhesión: el consumidor vs. autonomía de la voluntad}

Con la aparición de los contratos de adhesión se generaron grandes controversias acerca de los requisitos y cumplimiento de los presupuestos para la formalización del contrato, pues es necesario tener en cuenta que cambia la connotación de la posibilidad de concesiones recíprocas respecto del contenido del iter contractual; respecto al contrato de adhesión en relación con el principio de la autonomía de la voluntad que debe imperar en toda relación negocial, se trae el siguiente desarrollo: El contrato de adhesión es "aquel en el cual el contenido contractual ha sido determinado con prelación por uno solo de los contratantes al que se deberá adherir el co-contratante que desea formalizar una obligación jurídica obligatoria" (Vallespinos, 1984, p.238).

Actualmente se define en el Estatuto del consumidor así: "Aquel en el que las cláusulas son dispuestas por el productor o proveedor, de manera que el consumidor no puede modificarlas, ni puede hacer otra cosa que aceptarlas o rechazarlas" (Articulo 5 numeral 4 ley 1480 de 2011).

Acorde con lo anterior se establece que los contratos de adhesión representan un acuerdo en que una parte acepta las cláusulas predispuestas por la otra, las cuales no son objeto de modificación; estas se disponen para que se acepten o rechacen de manera íntegra, sin que quepa la posibilidad de cambios al respecto.

En cuanto a estos contratos la jurisprudencia ha tratado de explicar su naturaleza:

Pese a los cuestionamientos, que en lo relativo a la autonomía de la voluntad y el equilibrio negocial, entre otros aspectos, puede suscitar la contratación ajustada mediante la adhesión a estipulaciones predispuestas, es innegable 
que irreductibles factores de indole económica la han consolidado como una modalidad característica de las operaciones jurídicas contemporáneas. En efecto, el inusitado incremento de la producción derivado del tránsito de la manufacturación artesanal a la industrial trajo consigo la necesidad de ofrecer, con la mayor eficacia y el menor costo posible, los bienes y servicios producidos, de manera que la distribución a grandes escalas impuso la negociación en masa, al punto que los modelos de mercado prescindieron de los tratos individuales y de la intervención de personas con poder de negociación del contenido del acto jurídico, y, en su lugar, surgió el contrato de adhesión caracterizado porque el empresario predisponente somete a consideración del potencial cliente un reglamento convencional inmodificable al cual queda vinculado por la mera aceptación. (C.S.J Sentencia de 4 de noviembre de 2009, Sala de Casación Civil, M.P. Pedro Octavio Munar Cadena).

Ballesteros Garrido (las condiciones generales de los contratos y el principio de autonomía de la voluntad, 1999, p. 36) advierte que la forma de contratación por adhesión se usa no solo para agilizar las operaciones, para lograr mayor eficiencia, para reducir costos, sino para asegurarse una posición de prevalencia en los acuerdos, pues beneficia exclusivamente al predisponente a través de la imposición de prestaciones desequilibradas e injustas.

El uso de la contratación por adhesión supone riesgos y beneficios, su actividad está condicionada a los controles de que no sean usados para imponer beneficios abusivos en perjuicio de deudor. (Ordoqui, 2010, p. 173).

1 contrato de adhesión desde su aparición generó debate en la doctrina acerca de su verdadera naturaleza jurídica, al respecto surgieron varias posiciones, la tesis contractualista que defendía la existencia de un acuerdo de voluntades en estos contratos, la tesis anti-contractualista, cuyo principal exponente fue Duguit, que negaba la existencia de un verdadero acuerdo de voluntades. Sin embargo, hoy a pesar que aún existe esta discusión no se le niega la categoría de verdadero contrato, al contrato de adhesión. (Villalba, 2009, p. 144).

A su vez, respecto de la autonomía de la voluntad, se extraen las siguientes citas donde se expresan algunos postulados que servirán para conceptualizar el tema en el contexto del contrato de adhesión.

El postulado de la autonomía de la voluntad privada, consiste precisamente en ese reconocimiento más o menos amplio de la eficacia jurídica de ciertos actos o manifestaciones de voluntad de los particulares. Con otras palabras: consiste en la delegación que el legislador hace en los particulares de la atribución o poder que tiene de regular las relaciones sociales, delegación que estos ejercen mediante el otorgamiento de actos o negocios jurídicos. (Ospina, 2005, p.6).

Es importante tener claro que frente a los contratos, la autonomía de la voluntad siempre prevalecerá como requisito fundamental, para la celebración de los mismos, ya que es a través de esta, que los particulares manifiestan su consentimiento frente a cualquier negocio que se genere en la sociedad. Por consiguiente, es importante 
tener en cuenta la siguiente apreciación: La autonomía se manifiesta como poder de creación, modificación o extinción de dichas relaciones jurídicas y como poder de reglamentación de las situaciones privadas creadas, modificadas o extinguidas. De ahí que el poder individual se presente en un doble sentido, ya sea como poder de constitución de relaciones jurídicas y como un poder de reglamentación del contenido de tales relaciones jurídicas ${ }^{1}$ (Fernández, 2000, p.223).

Es así que se puede evidenciar la importancia que la autonomía de la voluntad representa en los contratos, y es ese carácter para regular su contenido, el que la legislación ha puesto en manos de los particulares. Se hace énfasis en el contrato de adhesión, con características especiales dentro de las cuales existe mayor probabilidad de generación de actos referentes a falta de información, o esta se da en forma incompleta, solo para señalar una situación específica, con el fin de alcanzar lo deseado por alguna de las partes y en algunas de las ocasiones por parte del empresario o predisponente.

Dentro de las exigencias legales para que se entienda dado el consentimiento por parte del consumidor en el contrato de telefonía móvil, según el artículo 37, Ley 1480 de 2011, se pueden establecer las siguientes:

(...) cuando se ha informado suficiente, anticipada y expresamente al adherente sobre la existencia efectos y alcances de la condiciones generales (...) en idioma castellano, cuando estas condiciones son concretas, claras y completas y cuando son contratos escritos, los caracteres deberán ser legibles a simple vista.

En complemento a la anterior afirmación se exponen las siguientes citas:

El hecho que se trate de un contrato de adhesión, no quiere decir que no requiera el consentimiento de ambas partes a la hora de perfeccionarse. El usuario debe manifestar expresamente su voluntad de adherirse al contrato facilitado por el proveedor. El consentimiento del proveedor no debe constar expresamente, pues éste se presume desde el momento cuando le es otorgado el contrato al cliente, e incluso su consentimiento se puede desprender de la publicidad utilizada, por cuanto cualquier oferta sería una manifestación de su voluntad.

Se dice que el Contrato de adhesión de telefonía móvil, es un contrato consensual puesto que la sola manifestación de la voluntad de las partes es suficiente para dar vida al contrato. Esto quiere decir que el contrato se perfecciona con el simple acuerdo entre las partes. El perfeccionamiento del Contrato de adhesión de Telefonía Móvil que de darse por cualquiera de los medios aceptados por la regulación, siempre y cuando la voluntad de las partes haya sido debidamente exteriorizada. La única exigencia que se desprende de la regulación es que las condiciones contratadas consten por escrito (Donato, 2012, p.62). 
(...) el concepto de autonomía privada comprende: “(...) decidir si se contrata o no; establecer con quién se contrata; escoger la figura iuris; obrar personalmente o valiéndose de un intermediario; escoger el medio o la forma de expresión y, por último, determinar libremente el contenido del negocio, o mejor, ejercer la libertad de configuración interna del contrato" (Hinestroza, 2002, p. 400-411), lo cual resulta importante, pues como el contrato, es ley para las partes (Art. 1602 C.C), debe quedar establecido de tal manera que en su celebración se plasme su verdadero querer, y de esta manera evitar inconvenientes en su interpretación y posterior ejecución. (Plata, 2010, p. 202).

Para concluir con este argumento, es necesario aclarar, que respecto a la intervención, en la definición y el contenido del contrato, cada una de las partes, tiene derecho a discutir, sugerir y cambiar el clausulado del contrato de acuerdo a su querer (causa para la realización del contrato); esto en la concepción tradicional no ofrece discusión, puesto que las partes no se tienen que adherir a lo establecido por la otra parte, situación que difiere de la realidad del contrato de adhesión, ya que es claro que el consumidor en este contrato, sólo presta su voluntad para aceptar o rechazar el clausulado creado por la otra parte que en este escrito se ha designado como predisponente. En razón a esta situación en Colombia se le brinda protección a través de la legislación al consumidor, no obstante ello, es evidente que el mundo de los contratos de adhesión representa un riesgo para el consumidor, por el hecho de que una de las partes de este contrato tiene mayor potestad y al contar con este ímpetu o dominio, la probabilidad de incurrir en actos nocivos para el consumidor aumenta.

Ahora bien, dentro de esos actos nocivos para el consumidor, en que el predisponente puede incurrir en faltas frente al ejercicio de la libertad de elección de determinado contratante, de ausencia de información suficiente para decidir si se contrata o no, entre otras situaciones de desventaja para el consumidor, están las denominadas cláusulas abusivas, las cuales se estudian a continuación en el contexto del contrato de telefonía móvil, habida cuenta que este contrato reúne las características de un contrato de adhesión, en el cual se incorporan las ya revisadas cláusulas de permanencia mínima.

\section{Cláusulas abusivas una revisión al contrato de telefonía móvil}

Las cláusulas abusivas se pueden presentar en cualquier tipo de contrato, sin embargo es más frecuente su incorporación en los contratos con condiciones predispuestas, dentro de los cuales están los contratos de telefonía móvil. 


\section{Cláusulas abusivas}

En un contexto general se puede decir que aquellas cláusulas impuestas y generadoras de un desequilibrio entre las obligaciones de las partes, se consideran abusivas. Al respecto se extraen dos definiciones que dan razón de su contenido.

Primero en el Estatuto del consumidor en Colombia se hace la siguiente apreciación:

Son cláusulas abusivas aquellas que producen un desequilibrio injustificado en perjuicio del consumidor y las que, en las mismas condiciones, afecten el tiempo, modo o lugar en que el consumidor puede ejercer sus derechos. Para establecer la naturaleza y magnitud del desequilibrio, serán relevantes todas las condiciones particulares de la transacción particular que se analiza. Los productores y proveedores no podrán incluir cláusulas abusivas en los contratos celebrados con los consumidores, En caso de ser incluidas serán ineficaces de pleno derecho. (Articulo 42 Ley 1480 de 2011).

Y como segunda cita se trae la siguiente apreciación dada por Laguado Giraldo: "Las cláusulas abusivas resisten todo el reproche del derecho pues violan la equidad natural y generan un desequilibrio manifiesto entre las obligaciones, cargas y derechos de las partes" (Laguado, 2003, p. 245).

Es así, que dentro de las cláusulas que se pueden constituir como abusivas está la cláusula de permanencia mínima cuando su establecimiento no cumple los parámetros establecidos por el ordenamiento jurídico, no por el hecho de pactarla en estos contratos se consideran abusivas, sino en el momento en que esta permanencia se convierte en el sustento ideal para que el proveedor incurra en actos de mala fe, por ejemplo, en el caso de las prórrogas automáticas o en el caso de sobrepasar los límites que a través de principios constitucionales se protegen en la contratación en Colombia, ya desarrollados. Cualquiera de estas situaciones que comporte una carga desequilibrada de obligaciones se puede considerar como abusiva.

Consolidado este desarrollo, es fundamental establecer dentro de la naturaleza del contrato de telefonía móvil, los momentos jurídicos que se relacionan con el establecimiento de cláusulas abusivas.

\section{Momentos del contrato de telefonía móvil}

Antes de entrar a definir los momentos de este contrato, es importante entender su naturaleza, por lo tanto, se extrae inicialmente una definición precisa acerca del contrato de servicio telefónico, dada por la autora Olga Lucía Alfonso Velázquez, como una aproximación a la definición concreta del contrato de telefonía móvil, dado de la siguiente manera:

(...) es contrato de servicio telefónico disponible al público todo contrato por el cual un operador se obliga a prestar a un usuario el servicio telefónico disponible al púbico y acaso otros servicios accesorios o relacionados y el 
abonado como contraprestación le paga por ello un precio (Alfonso, 2012, p.30).

El contrato de adhesión de telefonía móvil es el contrato por medio del cual el abonado se adhiere a las cláusulas predispuestas por un proveedor del servicio de telefonía móvil, a efectos de que el abonado por medio de un terminal pueda acceder y hacer uso de la red pública de telecomunicaciones mediante la cual el proveedor presta sus servicios, con el fin de comunicarse con los demás usuarios de las redes públicas de telecomunicaciones existentes; a cambio de una contraprestación que, usualmente, consiste en una remuneración económica (Donato, 2012, p.52).

Respecto a la anterior cita y al desarrollo que se ha dado en cuanto a los contratos de adhesión, se entiende que el contrato de telefonía móvil responde a las características de aquel, esto en concordancia con lo dispuesto en el artículo 5 numeral 4 de la ley 1480 de 2011, es un contrato con un clausulado dispuesto por un proveedor, en el cual el consumidor no tiene la posibilidad de cambiar estas condiciones, sino únicamente la opción de aceptarlo o rechazarlo tal y como se lo presenta el proveedor de servicios de telefonía móvil. Por lo tanto, los momentos jurídicos de un contrato de telefonía móvil responden a los mismos de un contrato de adhesión.

Vallespinos respecto de esta modalidad de contratación señala:

En el contrato por adhesión deben ocurrir indispensablemente dos momentos jurídicos que denominamos "estipulación" y "adhesión". Además hemos remarcado como un carácter típico de la estipulación el hecho de que son emitidas las condiciones del contrato para ser aceptadas por el adherente en virtud de la superioridad que tiene el estipulante en la relación contractual, lo cual lleva implícito el requisito de adhesión y no de plena aceptación, es decir, no toda estipulación desembocará invariablemente en un contrato por adhesión, ello ocurrirá solamente cuando se encuentre con el segundo momento jurídico, con la adhesión (Vallespinos, 1984, p. 322).

Lo anterior lleva a reiterar que se presenta una diferencia en la concepción, entre el contrato de adhesión y el contrato en su sentido clásico, tenido en cuenta que aunque en ambos está dado el cumplimiento de los requisitos esenciales y dentro de estos el del consentimiento, respecto de la declaración de la voluntad común específicamente señalada, hay una modificación, toda vez que la voluntad en el contrato de adhesión se encuentra manifestada una vez el adherente decide aceptar las condiciones que le han sido señaladas previamente por el oferente.

Así como en el contrato clásico, existen dos momentos jurídicos, que son la formación y la ejecución, la primera referida al momento de la celebración del contrato y la segunda, a aquellas cuestiones que surgen en el desarrollo del mismo; en el contrato de adhesión también se dan dos momentos que son designados como la estipulación, en la cual se da la pre elaboración de este contrato, el cual se entiende celebrado con la adhesión, donde el usuario decide aceptar o no tales condiciones para entender este contrato perfeccionado y el segundo momento, que responde a la 
ejecución del contrato y se da después de celebrado, es decir, cuando ya nace a la vida jurídica y se desarrolla todo el clausulado pre estipulado a través de la prestación de un servicio.

Ahora cabe la obligación de revisar en qué etapa del contrato se puede incurrir en cláusulas abusivas, esto es, cuestionar si se da en la formación o en la ejecución del mismo, para ello en primer lugar se realizará una presentación de las diferentes circunstancias que se dan en los momentos ya establecidos anteriormente, aunado a la inclusión de una tercera etapa denominada por algunos autores como de consumación.

Es común distinguir tres fases en la vida del contrato: la de generación, la de perfección y la de consumación. La fase de generación del contrato comprende todos los actos encaminados a la formación de las voluntades contractuales, lo que se ha venido a denominar tratos preliminares; en ella las partes negocian el posible contenido del contrato y tratan de convencerse de la conveniencia de su celebración. La fase de perfección es aquella en la que propiamente se concluye el contrato por la concurrencia de las declaraciones de voluntad de las partes: la oferta y la aceptación, a partir de este momento los contratantes quedan obligados por el acuerdo al que han llegado, no pudiendo ya desvincularse del mismo unilateralmente. La fase de consumación, por último, está destinada al logro de la finalidad del contrato a través del cumplimiento de las prestaciones objeto del mismo. (Bercovitz, 2009, p. 667).

Empero, en la formación del contrato puede ocurrir que se dé la existencia de un desequilibrio en cuanto a conocimientos en la materia sobre la que versa el contrato entre las partes negociadoras, como ocurre cuando es un empresario y otra un consumidor, la buena fe le impone a la parte que se encuentra en mejor posición informar verazmente a la otra de todo aquello que conozca, o debiera conocer y sea objetivamente determinante para que esta decida adecuadamente sobre la conveniencia de celebrar el contrato. (García, 1991, p. 44).

Frente a la situación expuesta es necesario aclarar que no daría lugar a expresar la existencia de cláusulas abusivas, si se siguen los lineamientos correctos para la formación del contrato, si la información es expuesta con claridad, lo que no coartaría la voluntad esencial para su celebración; sin embargo, la categoría de un contrato con condiciones predispuestas abre la posibilidad de que el proveedor del servicio de telefonía móvil, aprovechándose de esta facultad, inserte cláusulas abusivas desde su formación, las cuales pueden pasar desapercibidas en el momento en que el usuario se va a adherir al contrato y se verán reflejadas en su ejecución, pero que legalmente la empresa entra a respaldarse no en la ejecución del contrato sino en la formación del mismo.

Al respecto la Corte Suprema de Justicia ha precisado:

En la formación del contrato y, específicamente, en la determinación de las cláusulas llamadas a regular la relación así creada, pueden darse conductas abusivas, ejemplo prototípico de las cuales lo suministra el ejercicio del llamado poder de 
negociación por parte de quien, encontrándose de hecho o por derecho en una posición dominante en el tráfico de capitales, bienes y servicios, no solamente ha señalado desde un principio las condiciones en que se celebra determinado contrato, sino que en la fase de ejecución o cumplimiento de este último le compete el control de dichas condiciones, configurándose en este ámbito un supuesto claro de abuso cuando, una posición de dominio de tal naturaleza resulta siendo aprovechada, por acción o por omisión, con detrimento del equilibrio económico de la contratación (Corte Suprema de Justicia, Sentencia 5670 de Febrero 02 de 2001, M.P. Carlos Ignacio Jaramillo Jaramillo).

Es así que se entiende que para que se den las denominadas cláusulas abusivas en la formación del contrato de telefonía móvil, y que la cláusula de permanencia u otro tipo de cláusula pueda constituirse como tal, debe generarse necesariamente un desequilibrio entre las obligaciones de las partes, por lo tanto, cuando se incorporen cláusulas en la formación del contrato a favor del proveedor, tiene que equipararse con todo el contenido del contrato, esto es, que las ventajas se compensen con los servicios que recibirá el usuario, ya que no sólo basta con su establecimiento sino que se debe generar desigualdad entre las obligaciones de los contratantes. Sin embargo, en el desarrollo del contrato que corresponde a su ejecución, la norma permite establecer actos de manera unilateral, los cuales pueden dar lugar a la existencia de cláusulas abusivas.

Respecto a los riesgos que conlleva la celebración de estos contratos, advertimos de la frecuente incorporación de cláusulas abusivas o vejatorias por el predisponente que unilateralmente elabora el contenido de las cláusulas generales. En efecto, debido a que en la contratación predispuesta no existe la etapa de la negociación o de tratativas previas, ni tampoco la colaboración de una parte contratante en el diseño del contenido del contrato, se presentan casos en los que la parte contratante que ha elaborado el contrato por adhesión o las cláusulas generales de contratación asa de su posición jurídica de predisponer, íntegra o parcialmente, el esquema contractual, e incorpora condiciones que exclusivamente lo benefician o que perjudican únicamente al contratante que se adhiere. Una forma usual, en nuestro medio, es la exoneración o el traslado de la responsabilidad de los productores/proveedores hacia los consumidores/ adherentes que se adhieren al contrato predispuesto, generando un desequilibrio en la relación contractual. (Soto, 2003, p.607).

Las razones que justificarían una intervención legislativa en desarrollo de la constitución (Arts. 13, 78, 83, 95 y 333) para controlar las cláusulas abusivas, podrían ser ilustradas por un hecho real y práctico, consistente en que los elementos de control sobre la formación del contrato no han sido suficientes para una protección eficaz contra las cláusulas abusivas que una parte fuerte puede imponer a su co-contratante, cuando preestablece el contenido contractual en un contrato por adhesión o en un contrato no negociado con condiciones generales predispuestas (Gual, 2009, p.32).

Ahora bien, para aquellas cláusulas que sí, se dan a conocer de forma adecuada y 
completa, presta el usuario su total consentimiento para la celebración del contrato, que desde su formación no presentan ambigüedad alguna, es posible que se genere en la ejecución de éste, aprovechamiento en desarrollo y sustento de la cláusula establecida en ese primer momento, que puede constituirse en abusiva; por ejemplo, en el caso de variación de tarifas, revisiones repentinas sin sustento y con costos, prórrogas automáticas sin cumplimiento de las directrices normativas para su incorporación, entre otras prácticas abusivas que son declaradas de manera unilateral por el empresario o proveedor del servicio de telefonía móvil.

\section{CONCLUSIONES}

De acuerdo con el desarrollo realizado en el presente artículo, es posible concluir lo siguiente:

En cuanto a la cláusula de permanencia, es necesario establecer que su incorporación en los contratos de condiciones predispuestas o de condiciones generales, y específicamente en el contrato de telefonía móvil, es viable su incorporación dada la naturaleza de esta, toda vez que se busca con su aparición en el contrato que la empresa pueda soportar los costos de inversión a partir de la sostenibilidad de los usuarios por un tiempo determinado que en todo caso, debe conocer previamente el consumidor, sin que la permanencia implique que esta no pueda ser terminada bajo una situación como el incumplimiento de las obligaciones pactadas por parte del prestador del servicio.

El consumidor dado el papel protagónico que representa en los actos de comercio, además de consolidar el ejercicio de las herramientas jurídicas para adquirir un bien o servicio, goza de especial protección a partir de las normativas que soportan la prestación de los diferentes servicios, es así que el establecimiento o determinación del tratamiento de situaciones como el aparecimiento de las cláusulas abusivas, constituyen un escenario propio de dicha protección.

Respecto al aparecimiento de las cláusulas abusivas en el contrato, para que tomen dicha denominación es necesario que se encuentren en un escenario en el que revisado el contrato en su conjunto generen un desequilibrio en las obligaciones adquiridas por las partes y, una vez, determinado su aparecimiento en el mismo, se brindan las herramientas legales que ya están reconocidas no sólo en el Estatuto del Consumidor, ley 1480 de 2011, sino en las normas específicas que regulan la materia, como es el caso de las directrices emanadas para la telefonía móvil celular, tales como son la ley 1341 de 2009, por la cual se definen principios y conceptos sobre la sociedad de la información y la organización de las Tecnologías de la Información y las Comunicaciones, y la Resolución 3066 de 2011, Régimen Integral de Protección de los Derechos de los Usuarios de los Servicios de Comunicaciones.

Además de la protección con la que actualmente cuenta el consumidor frente al posible establecimiento de cláusulas abusivas en un contrato con condiciones generales, expuesta de manera expresa en las diferentes normas, es importante 
resaltar que los principios constitucionales, en todo caso, respaldan las relaciones jurídicas y con injerencia real en las relaciones entre particulares.

La autonomía de la voluntad en los contratos de adhesión y más específicamente en los contratos de telefonía móvil, se enfrenta a la real voluntad del consumidor al momento de suscribir estos acuerdos. Sin embargo, no se ve transgredida, según la legislación colombiana que ampara este tipo de contratos, los cuales pese a que cuentan con unas condiciones que pueden convertirse en la oportunidad perfecta para el surgimiento de actos nocivos para el consumidor, son contratos que se celebrarán de forma masiva debido a la gran agilidad que en razón de su estructura se dan en el mercado en Colombia.

\section{REFERENCIAS}

Arrubla Paucar J. A. (1997) Contratos Mercantiles. Tomo I. Diké Editores. Medellín. Acuerdo 11 de 2006 Comisión Nacional de Televisión.

Alfonso Velázquez \& Olga Lucía (2010). El Contrato de Servicio Telefónico. Editorial Reus, Primera Edición, Madrid. p. 30.

Ballesteros Garrido J. (1999) Las condiciones generales de los contratos y el principio de autonomía de la voluntad. Bosch Barcelona

Betti E. (2008) Teoría General del Negocio Jurídico. Granada Editorial Comares, S.L.

Bercovitz Rodríguez R. (2009) Tratado de Contratos Tomo I concepto, limites, significación, requisitos, formación, forma, documentación, interpretación e integración, eficacia e ineficacia del contrato. editor: Tirant lo Blanch. Valencia.

Constitución Política de Colombia. Articulo 83. Promulgada el 4 de julio de 1991.

Código Civil Colombiano. Ley número 57 de 1887. Promulgado el 26 de mayo de 1873 en Colombia.

Comisión Nacional de Televisión, Concepto 88453 de 2009

Comisión Nacional de Televisión, Acuerdo 11 de 2006

Corte Constitucional, Sala Plena, Sentencia C-1141, M.P.Eduardo Cifuentes Muñoz de 2000

Corte Suprema de Justicia, Sentencia de 4 de noviembre de 2009, Sala de Casación Civil, M.P. Pedro Octavio Munar Cadena

Corte Suprema De Justicia, Sentencia 5670 de Febrero 02 de 2001, M.P. Carlos Ignacio Jaramillo Jaramillo

Chapman. (2004). El abuso del derecho de asociación en la creación de sindicatos.

Donato López C. (2012) El contrato de adhesión de telefonía móvil analizado desde la perspectiva de los derechos del usuario final de los servicios de 
telecomunicaciones, Tesis para optar por el grado de licenciatura de derecho. San Pedro, Ciudad Universitaria Rodrigo Facio.

Espinoza, Espinoza J. (2005) los principios contenidos en el título preliminar del Código Civil peruano de 1984, Lima, fondo editorial de la Pontificia Universidad Católica de Perú.

Estrada, Alexey J. (s.f) La eficacia entre particulares de los derechos fundamentales. Una presentación del caso colombiano. Ponencia

Estrada, Alexey J. (2000) La eficacia entre particulares de los derechos fundamentales. Universidad Externado de Colombia, Bogotá.

EstigarribiaBieber, M. (s.f) Las Cláusulas Abusivas en la Contratación con Consumidores en la Legislación Argentina

Fernández Sessarego C. (2000). El supuesto de la denominada 'Autonomía de la Voluntad' (Perú) Artículo de el libro Contratación Contemporánea editorial Temis Bogotá Colombia.

García Rubio M. (1991) Sobre el fundamento del deber de la información.

González Ramírez, A. (1998). Introducción al Derecho. (Tercera edición corregida y actualizada, Edición librería del profesional). Bogotá.

González Herranz, M. L \& Eguizábal Maza, R. (Contributor). (2005) La comunicación publicitaria en el entorno de protección al consumidor. España: Universidad Complutense de Madrid.

Gual Acosta J. (2009) El Control sobre las cláusulas abusivas un régimen en evolución. Revista IUSTA. Facultad de Derecho Universidad Santo Tomás Bucaramanga.

Granados Aristizábal J. (2012) Del contrato con el consumidor al contrato con asimetría de poderes: Una aproximación desde el derecho comunitario europeo de los contratos, articulo de revisión, Universidad Externado de Colombia.

Laguado Giraldo, C. A. (2003) Condiciones generales, cláusulas abusivas y el principio de la buena fe en el contrato de seguro. Pontificia Universidad Javeriana Bogotá.

Ley 142 de 1994, Régimen de los servicios públicos domiciliarios, Diario Oficial 41.433 del 11 de julio de 1994.

Ley 1328 de 2009, Por la cual se dictan normas en materia financiera, de seguros, del mercado de valores. Régimen de Protección al Consumidor Financiero. Diario Oficial No. 47.411 de 15 de julio de 2009.

Ley 1480 de 2011, Estatuto del Consumidor de Colombia. Diario Oficial No. 48.220 de 12 de octubre de 2011.

Ley 1341 de 2009, Por la cual se definen principios y conceptos sobre la sociedad de la información y la organización de las Tecnologías de la Información y las Comunicaciones -TIC-, se crea la Agencia Nacional de Espectro y se dictan otras disposiciones. Diario Oficial No. 47.426 de 30 de julio de 2009.

Mendoza Palacios (2007) Contratos de adhesión CEAS.doc. 
Ospina Fernández G. \& Ospina Acosta E. (2005) Teoría General del Contrato y del Negocio Jurídico. Séptima edición. Temis.

Ordoqui Castilla G. (2010) Abuso del Derecho, civil, comercial, procesal, laboral y administrativo. (2 ${ }^{a}$ Edición). Pontificia Universidad Javeriana. Bogotá.

Ortiz Torres A.D \& Quintero Lee J. A (2008). Derecho del consumidor en el marco del tratado de libre comercio con Estados Unidos de América. Universidad Colegio Mayor de Nuestra Señora del Rosario Facultad de jurisprudencia pregrado Bogotá.

Parra Rodríguez C. (2001) El nuevo Derecho Internacional de los Contratos Parte Segunda. Principios de regulación de las obligaciones y contratos. J.M. Bosch editor.

Palao Moreno G. (2005) La protección de los consumidores en el ámbito comunitario europeo, en Derecho privado de consumo, 88 (María José Reyes, coord., Tirant Lo Blanch, Valencia)

Plata Sarmiento, E. del P. (2010). Teoría del contrato vs. Contrato de condiciones generales. Primera edición Octubre de 2010. Segundo Congreso Internacional de Derecho Empresarial y Contractual, Organización y Actividad Empresarial

Rinessi, Antonio J. (2006) Relación de consumo y derechos del consumidor. Editorial Astrea 512 páginas.

Reich, N. (1985) Mercado y Derecho, Ariel, Barcelona, p 159, 160.

Resolución 3066 de 2011. Régimen Integral de Protección de los Derechos de los Usuarios de los Servicios de Comunicaciones. Promulgada el 18 de mayo de 2011 por la Comisión de Regulación de Comunicaciones.

Resolución 2595 de 2010. Por la cual se modifican los artículos 7, 16, 44, 55, 75 y 81, se adiciona un anexo y se deroga el artículo 92 de la Resolución CRT 1732 de 2007. Publicado en el Diario Oficial 47.797 del 10 de agosto de 2010.

Serrano Alonso E. (s.f) interpretación de los contratos de adhesión ponencia.

Soto Coaguila C. (2003). Las Cláusulas Generales de Contratación y las Cláusulas abusivas. Universitas.

Solarte Rodríguez A. (2004). La buena fe contractual y los deberes secundarios de conducta. Articulo de investigación. Universidad Pontificia Javeriana Bogotá.

Suescún Melo J. (1.996) Derecho Privado. Estudios de Derecho Civil y Comercial Contemporáneo. Cámara de Comercio de Bogotá - Universidad de Los Andes. Bogotá.

Torrealba Navas, Federico. (2009). Lecciones de Contratos. Edición Personal. San José, Costa Rica. p. 76

Uribe Holguín, R. (1982) De las obligaciones y de los contratos en general.-- Bogotá: Editorial TEMIS Librería.

Valencia Zea, A. (1998). Derecho civil de las obligaciones. (T.III, Edit. Temis). Bogotá. 
Valencia Zea A. (1981) Derecho Civil. Tomo I Parte General y Personas. Novena Edición. Editorial Temis Bogotá.

Vallespinos, C. (1984). El Contrato por Adhesión a Condiciones Generales. Editorial Universidad de los Andes.

Villalba Cuéllar J.C. (2009) La Noción del Consumidor en el derecho comparado y en el derecho colombiano. Universidad Militar Nueva Granada. 